\title{
ANÁLISE DA COMPOSTAGEM DOS RESÍDUOS SÓLIDOS ORGÂNICOS NO MUNICÍPIO DE ITAPAGIPE/MG
}

\author{
ANALYSIS OF COMPOSITION OF ORGANIC SOLID WASTE IN THE \\ MUNICIPALITY OF ITAPAGIPE / MG
}

\author{
Isadora Ferreira Morais de Vasconcelos ${ }^{1}$ \\ Welington Arantes Filho ${ }^{2}$ \\ João Divino dos Santos Silva ${ }^{3}$
}

RESUMO: Um dos maiores problemas dos municípios brasileiros atualmente é o manejo dos resíduos sólidos, o que traz a tona a crescente busca por alternativas economicamente viáveis de reciclagem e reutilização dos resíduos resultantes das diversas atividades humanas. A compostagem é uma técnica que utiliza resíduos orgânicos em geral para a produção de um composto capaz de melhorar as características físicas e químicas do solo. $\mathrm{O}$ presente trabalho visa analisar se a compostagem é uma alternativa que pode ser utilizada na diminuição da quantidade de resíduos que são encaminhados para o aterro no município de Itapagipe-MG, visto que grande parte dos resíduos produzidos no município são de origem domiciliar e orgânica. Com o método Quali-quantitativo e Analise bibliográfica, conclui-se que a compostagem é sim uma alternativa viável para o município de ItapagipeMG, o município já possui uma Usina de Tratamento de resíduos e vem investindo na gestão de resíduos. É necessário ainda que a Usina funcione com capacidade total pois, atualmente é realizada apenas a separação dos resíduos, e que a população participe ativamente do processo porque os resíduos orgânicos precisam ser separados em sua origem, ou seja, os domicílios.

Palavras-chave: Sustentabilidade Ambiental. Reciclagem. Ambiente Urbano.

ABSTRACT: One of the biggest problems facing Brazilian municipalities today is the management of solid waste, which highlights the growing search for economically viable alternatives for recycling and reusing waste resulting from various human activities. Composting is a technique that uses organic waste in general to produce a compost capable of improving the physical an chemical characteristics of the soil. This work aims to analyze whether composting is an alternative that can be used to reduce the amount of waste that is sent to the landfill in the municipality of Itapagipe-MG, since most of the waste produced

\footnotetext{
Graduanda em Engenharia Civil, Faculdade Aldete Maria Alves/FAMA, Iturama/MG. isadoraferreiraooo@gmail.com.

2 Graduando em Engenharia Civil, Faculdade Aldete Maria Alves/FAMA, Iturama/MG. welingtonfilhoog@gmail.com

${ }^{3}$ Mestre em Ciências Ambientais (Universidade Brasil), Especialista em Engenharia Sanitária, Graduado em Engenharia Civil, Coordenador e Docente do curso de Engenharia Civil da Faculdade Aldete Maria Alves/FAMA, Iturama/MG.professorjd@outlook.com
} 
in the municipality is of household and organic origin. With the Quali-quantitative method and Bibliographic analysis, it is concluded that composting is a viable alternative for the municipality of Itapagipe-MG since the municipality already has a Waste Treatment Plant and has been investing in waste management. It is also necessary for the plant to operate at full capacity, as currently only the separation of waste is carried out, and that the population actively participates in the process because organic waste needs to be separated in its origin, that is, the households.

Keywords: Environmental Sustainability. Recycling. Urban Environment.

\section{INTRODUÇÃO}

Com o crescimento desordenado das cidades em virtude de fatores como: êxodo rural, qualidade de vida, etc., houve um aumento da população nas áreas urbanas e consequentemente houve um crescimento da produção de resíduos sólidos. Portanto a implantação de uma coleta seletiva destes resíduos será uma alternativa viável, uma vez que estes materiais retornaram a cadeia produtiva e também diminuirá o volume de resíduos enviado aos aterros sanitários.

A gestão adequada destes resíduos sólidos é essencial na busca pela melhoria da qualidade de vida da população, resultante da minimização, sobretudo, dos impactos negativos decorrentes do mal gerenciamento desses resíduos.

Neste contexto, o atendimento das diretrizes impostas pela Política Nacional de

Resíduos Sólidos (PNRS), Lei Federal n⿳0 12.305 de 02 de agosto de 2010, mostra-se fundamental (BRASIL, 2010).

Portanto, é fundamental definir um sistema de gestão sustentável de resíduos sólidos municipais, promover saúde e bem-estar à população e garantir a sustentabilidade do ambiente urbano.

Cerca de 50\% dos resíduos domésticos produzidos nas cidades são orgânicos, a compostagem é um processo no qual são aproveitados diversos tipos de resíduos orgânicos e que quando adicionados ao solo são capazes de melhorar suas características físicas e biológicas. Se utilizada no reaproveitamento desses resíduos a compostagem atua na melhoria das condições ambientais das cidades e da saúde da população em geral.

Atualmente, o destino da maior parte dos resíduos sólidos urbanos produzidos nas cidades são os lixões e aterros controlados, altamente nocivos ao meio ambiente devido a contaminação do solo e lençóis freáticos. Tal situação pode ser contornada através de 
execução de projetos, visando à separação dos materiais que podem ser reciclados e reaproveitando os resíduos sólidos orgânicos e encaminhando-os a compostagem.

A compostagem é uma técnica simples e de baixo custo provavelmente o mais antigo sistema de tratamento biológico utilizado pelo homem, tendo sido utilizada pelas antigas civilizações como um método natural de reciclagem dos nutrientes, comumente presentes nos resíduos resultantes das suas atividades diversas (PEREIRA-NETO, 2007).

Para os autores (OLIVEIRA; SARTORI; GARCEZ, 2008) a compostagem é um processo de oxidação biológica através do qual os microrganismos decompõem os compostos constituintes dos materiais liberando dióxido de carbono e vapor de água. Apesar de ser considerada pela maioria dos autores como um processo aeróbio, a compostagem é também referida como um processo biológico de decomposição anaeróbia, sendo realizada em sua quase totalidade por processos aeróbios.

Diante do problema, o trabalho se propôs, como objetivo geral, nortear o processo de reciclagem dos resíduos orgânicos domiciliares do município, através do processo de compostagem, dando um destino correto aos resíduos sólidos orgânicos domiciliares.

Os objetivos específicos definidos foram: (a) refletir como a compostagem dos resíduos sólidos domiciliares contribui para o município de Itapagipe/MG. (b) verificar qual a participação da população no processo de compostagem. (c) apresentar-se quais são as etapas do processo de compostagem.

Assim sendo, frente aos desafios propostos, o presente artigo estruturou-se inicialmente abordando os aspectos legais e teóricos. Finalmente foi elaborada uma pesquisa de campo no município em estudo, acompanhando a produção e destino dos resíduos sólidos, com a apresentação dos resultados obtidos.

\section{POLÍTICA NACIONAL DE RESÍDUOS SÓLIDOS}

De acordo com a Constituição Federal:

Todos têm direito ao meio ambiente ecologicamente equilibrado, bem de uso comum do povo e essencial à sadia qualidade de vida, impondo-se ao Poder Público e à coletividade o dever de defendê-lo e de preservá-lo para as presentes e futuras gerações. (BRASIL, 1988, art. 225).

A constituição Federal preocupou-se com a preservação do meio ambiente e abriu precedente para que a União definisse mecanismo que atendessem ao artigo supracitado, 
terminando na elaboração e promulgação da Política Nacional dos Resíduos Sólidos (PNRS).

O resíduo sólido orgânico de origem domiciliar tem trazido grandes problemas ao meio ambiente em relação a sua destinação adequada, e no enquadramento na Política Nacional de Resíduos Sólidos (PNRS), Lei 12.305 de 2010.

A PNRS abrange todos os resíduos sólidos inclusive aqueles que não podem ser reaproveitados e traz como ponto principal o trabalho conjunto do poder público, iniciativa privada e sociedade civil.

Entre os principais pontos que a PNRS trata estão:

Proteção da saúde pública e da qualidade ambiental; Não geração, redução e reutilização dos resíduos; Estimulo a adoção de padrões sustentáveis de produção e consumo; Adoção, desenvolvimento aprimoramento de tecnologias limpas como forma de minimizar impactos ambientais.

A lei prevê, como incentivo à coleta seletiva e à reciclagem, práticas de educação sanitária e ambiental, incentivos fiscais, responsabilidade compartilhada e a logística reversa.

A responsabilidade compartilhada nada mais é do o compromisso dos comerciantes, distribuidores, fabricantes, importadores, cidadãos e etc., sobre o ciclo de vida de um produto.

Já a logística reversa prevê que os fabricantes de produtos como agrotóxicos, pilhas, baterias, pneus e etc., se preocupem em saber qual será a destinação que o usuário final dará ao seu produto após o uso e fornecer opções para reaproveitá-lo em suas cadeias produtivas ou descartá-lo corretamente, e cabe ao usuário devolver embalagens e produtos as empresas.

No art. 36, inciso V, a PNRS trata a necessidade de implantação, "de sistemas de compostagem para resíduos sólidos orgânicos e articulação com os agentes econômicos e sociais formas de utilização do composto produzido". Tornando a promoção da compostagem, a implantação da coleta seletiva e da disposição final ambientalmente adequada dos rejeitos, parte das obrigações dos municípios instituída pela Lei 12.305/2010.

Ao analisar a lei, nota-se o estabelecimento de prioridades em relação ao gerenciamento de resíduos sólidos, começando pela não geração dos mesmos, seguido de redução, reutilização, reciclagem, tratamento e destinação ambientalmente adequada dos rejeitos (ALBERTONI, 2013). 
Em 2010 o Ministério do Meio Ambiente - MMA, publicou o Manual Para Implantação da Compostagem e Coleta Seletiva no Âmbito de Consórcios Públicos, que nada mais é que um projeto de cooperação técnica para a melhoria da gestão ambiental urbana no Brasil.

No manual o MMA trazia a transformação da coleta seletiva e a compostagem em um serviço público universal. Segundo o manual:

\footnotetext{
O uso de matéria orgânica como adubo é bem antigo - a observação do processo natural de formação de uma camada de húmus sobre o solo pela decomposição de folhas e galhos caídos sobre a terra permitiu reproduzi-lo de forma organizada, planejada e controlada para se obter adubo. Para os serviços de manejo de resíduos sólidos, o objetivo não é exatamente produzir adubo - o que move o processo não é o produto, mas o fato de que a matéria orgânica presente no lixo pode ser transformada e reaproveitada, desviando resíduos que normalmente teriam que ser aterrados
}

\section{I Saneamento Básico}

A PNRS é integrada com a Política Nacional de Educação Ambiental (Lei n 9.795 de 27 de abril de 1999), e com a Política Federal de Saneamento Básico (Lei no 11.445 , de cinco de janeiro de 2007).

De acordo com o art. $\mathrm{I}^{\circ}$, da Lei $\mathrm{n}^{\circ}$ 9.795:

Entende-se por educação ambiental os processos por meio dos quais o indivíduo e 406 a coletividade constroem valores sociais, conhecimentos, habilidades, atitudes e competências voltadas para a conservação do meio ambiente, bem de uso comum do povo, essencial à sadia qualidade de vida e sua sustentabilidade.

A alínea c, do artigo $3^{\circ}$, da Lei no ${ }^{\circ}$ Ir.445 define saneamento básico como um conjunto de serviços como a "limpeza urbana e manejo de resíduos sólidos: conjunto de atividades, infraestruturas instalações operacionais de coleta, transporte, transbordo, tratamento, destino final do lixo doméstico e do lixo originário da varrição, limpeza de logradouros e vias públicas”.

O manejo dos resíduos sólidos de um município engloba não só os resíduos domiciliares como também os comerciais, industriais e de vias públicas.

Segundo a cartilha do IBGE Saneamento Básico Avanços e Desafios, todos os estados com exceção do Piauí têm mais de $80 \%$ de seus domicílios urbanos atendidos pela coleta de lixo, tornando-a o serviço de saneamento básico com maior área de abrangência no país, mais de $97 \%$ dos domicílios urbanos brasileiros são atendidos pela coleta de lixo. 
Mesmo com uma coleta de resíduos bem equacionada um dos maiores problemas das cidades brasileiras atualmente ainda é a destinação correta e o controle da gestão dos resíduos domiciliares.

Segundo o IBGE 95\% das latas de alumínio são recicladas no Brasil, outros materiais como papel, plástico e vidro têm índices de reciclagem inferiores a 50\%. Além disso, a maior parte desse trabalho é realizada por catadores autônomos ou cooperativas de reciclagem e não pela participação ativa da população e comprometimento das autoridades com a separação e coleta seletiva do lixo.

Um fator muito importante no manejo dos resíduos é a conscientização da população sobre a responsabilidade que cada cidadão possui nesse processo.

As áreas de descarte inadequadas de resíduos orgânicos são habitadas por vetores como ratos, baratas, vermes e outros agentes nocivos à saúde. Tratando esses resíduos de maneira adequada, contribuímos para a manutenção da saúde das pessoas, reduzindo os riscos a saúde.

Só em 2015, de acordo com o Ministério do Meio Ambiente, foram geradas cerca de 32 milhões de toneladas de resíduos orgânicos no Brasil, o que equivale a 88 mil toneladas de lixo diário. Todo este material quando entra em decomposição, seja nos lixões ou aterros sanitários, gera o gás metano, um dos principais causadores do efeito estufa. Associada a essa questão está a reciclagem e a reutilização desses resíduos.

\subsection{Plano Municipal de Gestão Integrada de Resíduos Sólidos e a Participação da População no Processo de Compostagem}

A geração de resíduos é a primeira etapa a ser definida para a gestão dos mesmos. Nem sempre todo o resíduo gerado é coletado, por motivos como disposição irregular, coleta informal e insuficiência do sistema de coleta público (IBAM, 20II).

A elaboração do Plano Municipal de Gestão Integrada de Resíduos Sólidos é condição necessária para que o município tenha acesso aos recursos da União destinados à limpeza urbana e ao manejo de resíduos sólidos.

O município de Itapagipe-MG possui o PMGIRS - Plano Municipal de Gestão Integrada dos Resíduos Sólidos.

Segundo o PMGIRS:

Todos os cidadãos, assim como as indústrias, o comércio, o setor de serviços e ainda as instâncias do poder público possuem cada qual uma parte de responsabilidade pelos 
resíduos sólidos gerados no município. Portanto, a participação social foi fundamental no processo de elaboração do Plano Municipal de Gestão Integrada de Resíduos Sólidos - PMGIRS, pois possui caráter informativo, orientativo e possibilita a população se manifestar quanto à condição municipal no que diz respeito ao gerenciamento de resíduos. A Mobilização Social para efetiva participação da população na elaboração do PMGIRS utilizou de estratégias de comunicação para as divulgações das etapas do Plano e canais de comunicação para que a população pudesse se manifestar, com opiniões, sugestões e críticas, auxiliando na elaboração do PMGIRS.

A gestão dos resíduos sólidos urbanos em Itapagipe é realizada pela empresa terceirizada Quebec Construções e Tecnologia Ambiental S/A.

A empresa foi contratada para coletar os resíduos sólidos urbanos, realizar a coleta seletiva e triagem de material reciclado, a varrição de ruas e logradouros públicos e operar a UTC - Usina de Triagem e Compostagem.

A Quebec Ambiental realiza a coleta dos resíduos domiciliares, comerciais e industriais (com características domiciliares), de varrição e coleta seletiva da cidade.

A Prefeitura Municipal de Itapagipe através da Secretaria de Obras é responsável pela limpeza pública de praças, canteiros e avenidas ficando a cargo de coletar os resíduos de capina e poda de árvores, bem como coletar entulhos dispersos em ruas, avenidas e calçadas.

Para o PMGRIS foram criados um Comitê Diretor (CD) e um Grupo de Sustentação (GS), instâncias de coordenação e representação, para condução coletiva e consistente do processo instituídos pelo Decreto ${ }^{\circ}$ 44I de 03 de junho de 2015.

O Comitê Diretor formulava os temas para debate, exercendo também papel executivo nas tarefas de organização e viabilização da infraestrutura (convocatória de reuniões, locais apropriados, cópias de documentos etc.).

O Grupo de Sustentação, organismo político de participação social que se responsabilizava por garantir o debate e o engajamento de todos os segmentos ao longo do processo participativo.

Segundo o PMGRIS:

A primeira ação dos grupos de trabalho foi discutir a divisão do município em setores de mobilização, as estratégias para buscar o maior número de pessoas a participarem da elaboração do Plano e as formas de divulgação de cada etapa do.

A divisão do município em setores de mobilização social foi baseada na divisão do município em setores censitários, onde é possível identificar onde há o maior número de moradores, de acordo com a divisão adotada pelo IBGE. Levou-se em consideração também 
a questão da logística, a fim de facilitar o acesso da população, tanto da zona urbana quanto da zona rural, as apresentações do Plano.

Foram realizadas reuniões setoriais que propunham o debate aberto em comunidade possibilitando a população se manifestar e expor as necessidades e defasagens do saneamento municipal.

As reuniões setoriais foram previamente divulgadas por meio de cartazes fixados em murais, convites, divulgação em jornal de circulação local, rádio, carro de som e site da Prefeitura Municipal de Itapagipe. Os mesmos mecanismos de comunicação foram utilizados para divulgar Conferência Municipal de finalização do Plano.

Os resíduos sólidos urbanos são coletados diariamente de segunda a sábado, a coleta é realizada porta a porta, onde o caminhão compactador que possui capacidade de $7 \mathrm{~m}^{3}$ passa nas ruas e avenidas da cidade recolhendo os resíduos.

No município não existe nenhum Programa de Educação Ambiental definido e de grande abrangência, o que existe são ações individuais que ocorrem normalmente em escolas através de trabalhos que abordam temas como meio ambiente, reciclagem e saneamento básico.

No ato da implantação da coleta seletiva houve uma campanha de mobilização através de cartilha explicativa, orientando a população como é feita a separação dos resíduos recicláveis dos resíduos domiciliares e informando a rota e horários que passaria o caminhão da coleta seletiva.

Porém, relatos de moradores indicam que faltam informações quanto à rota percorrida pelo caminhão, dias e horários de recolhimento dos resíduos. Uma campanha de mobilização mais intensa, aliada a um programa de educação ambiental poderia se iniciar no município usando como tema inicial a coleta seletiva.

Através de cartilhas em uma linguagem simples e objetiva, rádio e palestras educativas para crianças, jovens e adultos seria possível incentivar a população a participar e aderir à separação do material reciclado, tornando a coleta seletiva mais eficiente, trabalhando a ideia de redução de resíduos e eliminação de pontos de descarte irregular.

\section{${ }_{3}$ Contribuição da Compostagem dos Resíduos Sólidos Domiciliares No Município}

Ainda segundo o PMGIRS o município de Itapagipe possui uma Usina de Triagem e Compostagem - UTC que funciona parcialmente, trata-se de uma construção 
relativamente nova, situada em um local de fácil acesso, em bom estado de conservação e bem estruturada, possui estrutura necessária para fazer a separação dos resíduos urbanos coletados diariamente, sendo composta por rampa de acesso para o caminhão despejar os resíduos, esteira, galpões para armazenamento temporário, pátio para compostagem, prensa e escritório administrativo.

Atualmente a única atividade desenvolvida na UTC é a segregação dos materiais provenientes da coleta seletiva, armazenagem temporária e prensa em fardos para venda. Se a UTC começar a operar com sua capacidade total instalada contribuirá com a redução de resíduos levados para a disposição final, uma vez que, conforme a composição gravimétrica realizada os RSU do município são compostos por $18,5 \%$ de material reciclado, que poderia ser separado e vendido, e cerca de $70 \%$ de matéria orgânica que poderia ser realizada compostagem.

Figura I. Resíduos produzidos no Município de Itapagipe-MG.

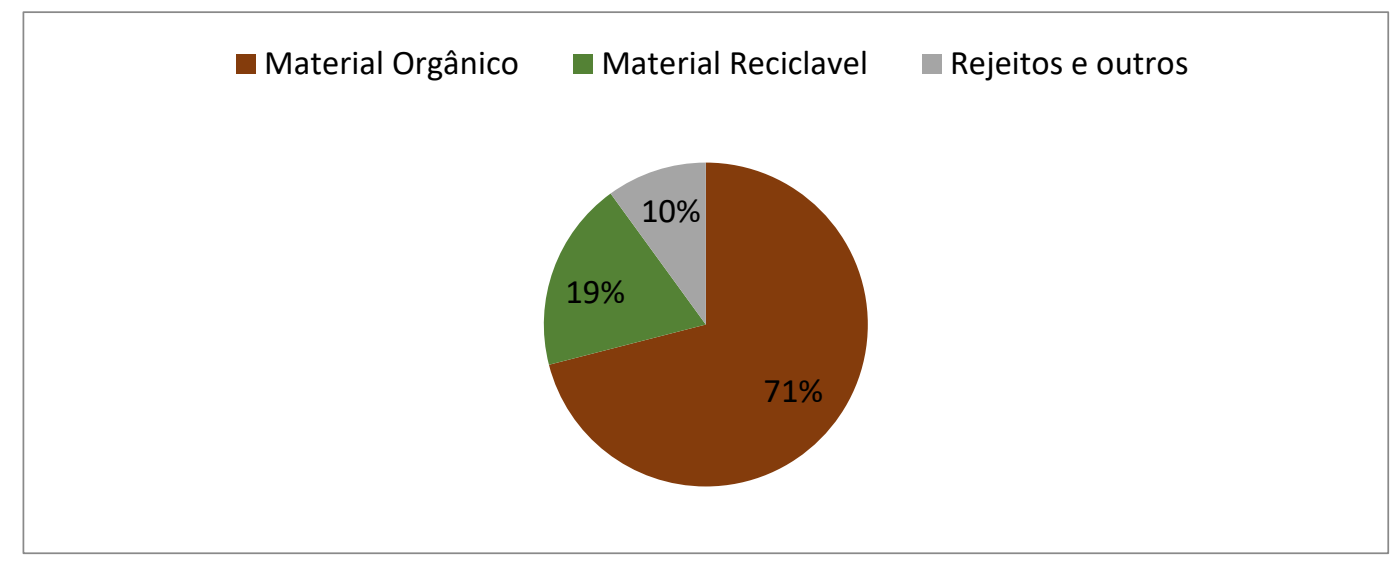

Fonte: Plano Municipal de Gestão de Resíduos Sólidos de Itapagipe-MG.

A fração orgânica dos resíduos em Itapagipe é superior a 70\% o que mostra o enorme potencial de matéria orgânica a ser compostada no município. De acordo com o Plano Nacional de Resíduos Sólidos (20II) os resíduos orgânicos correspondem a 5I,4\% dos resíduos sólidos urbanos (RSU) gerados no Brasil.

Para que a compostagem possa ser realizada é necessário que os resíduos sejam separados na sua origem, ou seja, é preciso que cada domicílio, comércio e indústria faça sua parte, garantindo assim a qualidade do resíduo orgânico. É muito importante também a coleta seletiva para o resíduo orgânico, depois de realizada a separação e coleta é que acontece de fato o processo de compostagem. 
Como já dito anteriormente a compostagem é uma das técnicas mais eficazes, antigas e baratas utilizadas na gestão de resíduos sólidos domiciliares. Nas casas os principais resíduos encontrados que podem ser compostados são restos de preparações alimentícias e sobras de refeições, que podem ser facilmente separados e entregues a coleta seletiva.

\section{FASES DO PROCESSO DE COMPOSTAGEM}

A compostagem é considerada alternativa sustentável, simples, eficaz e que atende a legislação ambiental em vigor - Política Nacional de Resíduos Sólidos (Lei 12.305/2010). O processo também contribui para a redução do aquecimento global.

A compostagem não se limita apenas à adição e mistura de materiais orgânicos em pilhas, mas envolve a escolha dos materiais, seleção do sistema de compostagem, o local onde será realizado, e a disponibilidade desses materiais para que processo se complete (KIEHL,1998).

È muito importante a separação doméstica dos resíduos orgânicos, pois a contaminação desses resíduos por materiais tóxicos dificulta a produção de biofertilizantes.

A compostagem é dividida em três fases: mesofilica, termofilica e por fim a maturação.

Figura 2. Esquema Simplificado do Processo de Compostagem.

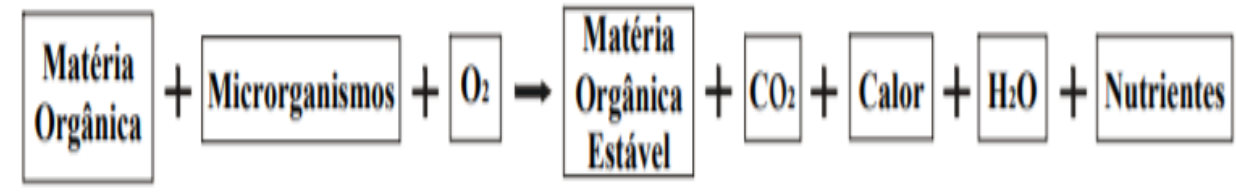

Fonte:

Fernandes e Silva, 1999, p.I6.

$\mathrm{Na}$ fase mesofilica ocorre à decomposição da matéria orgânica facilmente degradável, as moléculas mais simples. Estende-se por um período curto de cerca de io a is dias e mantém uma temperatura de cerca de $40^{\circ} \mathrm{C}$ que é a temperatura ideal para os microorganismos que realizam a decomposição nesse período. É comum colocar sobre o material uma camada de cerca de $10-30 \mathrm{~cm}$ de composto maduro para manter o equilíbrio interno do material (sem perda de calor e umidade).

A fase termofilica ocorre durante aproximadamente dois meses e a decomposição é realizada por fungos e bactérias termofílicos, apresenta temperaturas entre $65-70^{\circ} \mathrm{C}$ o que possibilita a eliminação de microorganismos patogênicos. 
A fase de maturação dura de i a 2 meses e é onde a atividade microbiana do composto irá diminuir gradativamente visto que a temperatura do composto também começa a baixar chegando a temperatura ambiente. A acidez do composto também se normaliza para que seja possível a utilização do mesmo no solo.

O húmus (composto) é um tipo de matéria orgânica mais resistente à decomposição pelos microorganismos. No solo, as substâncias húmicas vão sendo lentamente decompostas pelos microorganismos e liberando nutrientes que são utilizados pelas raízes das plantas.

\section{CONSIDERAÇÕES FINAIS}

Como vimos anteriormente a compostagem é uma técnica simples, barata e que vem sendo aprimorada pelo homem ao longo do tempo. Ela pode ser realizada com os resíduos resultantes das mais diversas atividades humanas, podendo ocorrer de maneira aeróbia e também anaeróbia. A decomposição da fração orgânica dos resíduos pode ser feita de maneira natural no meio ambiente ou controlada em usinas de compostagem e reciclagem. Sem sombra de dúvidas e respaldados pelas legislações vigentes podemos afirmar que a compostagem é a melhor entre as opções disponíveis para a maioria dos municípios brasileiros, mas que não é tão eficiente atualmente pela falta de políticas públicas de incentivo e a falta da participação da população nesse processo.

Levando em consideração que mais de 70\% dos resíduos sólidos do município de Itapagipe-MG são orgânicos, a compostagem seria uma ótima alternativa de reciclagem desses resíduos. Traria uma diminuição drástica na quantidade de resíduos que são dispostos no aterro controlado. Ajudando ainda no enquadramento do município nas diretrizes impostas pela PNRS que trata a compostagem como uma das melhores técnicas de reciclagem e reutilização.

De acordo com o próprio plano de gestão de resíduos do município de Itapagipe-MG se a UTC funcionasse com sua capacidade total seria possível a realização da compostagem e não só a separação do lixo como é realizada atualmente. Para isso seria necessário um maior investimento por parte do município e um aumento na participação da população, já que atualmente é realizada apenas a coleta seletiva e ainda assim a população não participa de maneira ativa.

Deve ser feita a estruturação correta do plano de gestão dos resíduos no município visando principalmente o incentivo à participação da população nas atividades. Medidas 
simples como: definir corretamente as rotas de coleta, dias, horários e até mesmo a forma que a coleta dos resíduos orgânicos será feita podem aumentar a participação dos habitantes do município já que essa foi uma das queixas registradas pelos próprios moradores nas reuniões de elaboração do plano de gestão de resíduos.

\section{REFERÊNCIAS}

ALBERTONI, Tais A. Caracterização física dos resíduos sólidos gerados em restaurante universitário. 2013. 77p. Trabalho de conclusão de curso de graduação apresentado à disciplina Trabalho de Conclusão de Curso 2. - Engenharia Ambiental, Universidade Tecnológica Federal do Paraná, Câmpus Londrina. Londrina, 2013.

BRASIL. Constituição da República Federativa do Brasil: D.O. 5 de outubro de 1988. Disponível em: www.mec.gov.br/legis/default.shtm. Acesso em: 20 jun. 2020.

BRASIL. Lei n. 9795 - 27 de abril de 1999. Dispõe sobre a educação ambiental. Política Nacional de Educação Ambiental. Brasília, 1999. Disponivel em: http://www.planalto.gov.br/ccivil_03/leis/l9795.htm\#: :text=LEI\%20No\%209.795\%2C\%20DE\%2027\%20DE \%20ABRIL\%2oDE\%201999.\&text=Disp\%C3\%B5e\%2osobre\%20a\%2oeduca\%C3\%A7\%C3\%A30\%2oambiental, Ambiental\%20e\%2od\%C3\%Ai\%2ooutras\%2oprovid\%C3\%AAncias.\&text=Art. Acesso em: 20 jun. 2020.

BRASIL. Lei no. II.445, de o5 de janeiro de 2007. Estabelece diretrizes nacionais para o saneamento básico; altera as Leis nos 6.766, de I9 de dezembro de 1979, 8.036, de II de maio de 1990, 8.666, de 2i de junho de 1993 , 8.987, de 13 de fevereiro de 1995; revoga a Lei no 6.528, de II de maio de 1978; e dá outras providências. Disponível em: http://www.planalto.gov.br/ccivil_03/_Ato2007-2010/2007/Lei/Lir445.htm. Acesso em: 15 jun. 2020.

BRASIL. Ministério do Meio Mabiente. Plano Nacional de Resíduos Sólidos. Versão preliminar apreciado pelos Conselhos Nacionais. Brasília: MMA, agosto 2012. Disponível em: 〈http://www.sinir.gov.br/web/guest/plano-nacional-de-residuos-solidos〉. Acesso em: or jun. 2020.

FERNANDES, F. \& SILVA, S.M.C.P. (1999) Manual prático para a compostagem de biossólidos. Rio de Janeiro: Associação Brasileira de Engenharia Sanitária e Ambiental. p.r6.

INSTITUTO BRASILEIRO DE ADMINISTRAÇÃO MUNICIPAL - IBAM. Manual de gerenciamento integrado de resíduos sólidos. Org. José Henrique Penido Monteiro...[et al.], coordenação técnica Victor Zular Zveibil. Rio de Janeiro: IBAM, 20or.

INSTITUTO BRASILEIRO DE GEOGRAFIA E ESTATISTICA - IBGE, Judicael Clevelario Junior. Saneamento Básico no Brasil Avanços e Desafios. Disponivel em: https://biblioteca.ibge.gov.br/visualizacao/livros/liv47603_cap5_pt4.pdf. Acesso em: o6 jun. 2020.

KIEHL, E. J. Manual de Compostagem: maturação e qualidade do composto. Piracicaba,:E. J. Kiehl, 1998.

MINAS GERAIS, Prefeitura Municipal de Itapagipe. Plano Municipal de Gestão Integrada de Resíduos Sólidos. Itapagipe-MG, 2015.

Ministério do Meio Ambiente - MMA. Manual Para Implantação de Compostagem e de Coleta Seletiva no Âmbito de Consórcios Públicos. https://www.mma.gov.br/estruturas/srhu_urbano/_arquivos/3_manual_implantao_compostagem_coleta_sel etiva_cp_I25.pdf. Acesso em: I5 jun. 2020.

OLIVEIRA, E.; SARTORI, R.; GARCEZ, T. Compostagem. Trabalho de Pós-Graduação em solos e nutrição de plantas - Escola Superior de Agricultura Luiz de Queiroz, Universidade de São Paulo, Piracicaba, 2008. 
PEREIRA NETO, J. T. Manual de compostagem: processo de baixo custo. Viçosa - MG: UFV, 2007.

PEREIRA NETO, João Tinoco. Manual de compostagem com processo de baixo custo. Belo Horizonte: UNICEF, 1996.

Política Nacional de Resíduos Sólidos, Lei 12.305. Diário Oficial da República Federativa do Brasil, Brasília, DF, 2 ago. 2010. Disponível em: Acesso em: 26 abr. 2020.

UNIVERSIDADE ESTADUAL PAULISTA. Compostagem doméstica de lixo. São Paulo: UNESP/Botucatu, 2002. 